\title{
ПРОБЛЕМА СОЦИАЛЬНОГО ВРЕМЕНИ В ФИЛОСОФИИ
}

\section{Е.В. Соколова}

XX век - век великих социальных преобразований и разложения отживших социальных форм - обнаруживает новое, неведомое прошлому и характерное для современности отношение ко времени, острое ощущение зависимости от него. В отличие от неторопливых, как нам кажется, эпических времен прошлого, действительность приобретает новую временную размерность, что требует научного переосмысления.

Социальное время выступает такой формой и таким условием общественной жизни, изучение которого может дать объективное и комплексное знание об обществе в целом, его истории и современной тенденции развития. Время характеризует любой акт человеческой деятельности, а значит, и эту деятельность можно описывать с помощью категорий социального времени.

Традиционно в философии время определяется как «форма бытия материи, выражающая длительность бытия и последовательность смены состояний всех материальных систем и процессов в мире» [6, с.94]. Оно не существует вне материальных изменений. Это определение, по сути своей, является физическим определением времени. Физическое время - это время существования материальных объектов, воспринимаемых человеком как объективно существующие.

Более узкая проблема - проблема социального времени, несмотря на большое количество работ по общим проблемам времени, остается малоизученной. А. Юбер еще в 1905 году определил время как символическую структуру, которая выражает организацию общества через временные ритмы (см.: [9, с. 132-133]). Понятие социального времени вошло в науку в $60-\mathrm{x}-70-\mathrm{x}$ годах, что свидетельствует о росте интереса

Актуальні проблеми духовності

(Відп. ред.: Я.В. Шрамко)

Кривий Ріг (2006), 401-409 
к этой проблеме и ее актуальности. Не имея еще понятийного статуса, не оформившись в достаточно содержательной дефиниции, оно сводилось либо к социальному инварианту физического времени, т.е. к своеобразной социальной метрике, либо трактовалось очень широко как временная форма социального бытия. Чаще всего оно выступало как своего рода общий знаменатель всех характеристик, применяемых к общественной жизни в ее статике (структура времени - по горизонтали) или динамике (структура времени по вертикали) [7].

Теоретически социальное время отлично от физического, так как напрямую зависит от деятельности людей. Это ставит перед нами сложнейшую проблему: в какой степени социальное время зависит от субъективного фактора, и по каким параметрам оно отличается от физического? Нам известны только некоторые свойства физического времени. Но насколько эти свойства объективны и постоянны, и каким образом время влияет на процессы, происходящие в нашей Вселенной, неизвестно.

Основными свойствами физического времени, которое мы наблюдаем, являются длительность, анизотропность, неповторяемость и непрерывность. Несомненно, что социальное время обладает первыми двумя характеристиками. Однако, что касается последних двух характеристик, вопрос представляется спорным и неоднозначным. Например, если говорить о такой характеристике как непрерывность, то, с одной стороны, непрерывность социального времени следует из непрерывности самого бытия социума, но, с другой стороны, отсутствие каких-либо значимых событий создает некий вакуум, пустоту, прерывистость цепи событий (по проблеме события как элемента исторического анализа см. [9]). Также многозначна проблема повторяемости социального времени. Примером этого являются определенные исторические закономерности, некая цикличность истории, о которой писали такие ученые как, например, О. Шпенглер и А. Тойнби.

Социальное время содержит социальные и индивидуальные представления, это - форма бытия социума, выражающаяся в смене последовательных событий. Оно не существует вне социальных изменений, и тем самым прослеживается четкая связь социального времени и деятельности. Именно деятельность формирует события, которые и являются сутью социального времени. Таким образом, время общества характеризуется длительностью чередования, последовательностью смены социальных явлений в их взаимодействии. Оно не существует вне деятельности, которая инициирует изменения (события). Понятие «событие» должно быть использовано как субстанциональ- 
ная категория, объяснительный принцип в понимании сущности социального времени. При этом нужно учитывать, что социальное время событий (линейное, прерывное, неповторяемое) и время культуры не являются равноправными.

В целом термин «социальное время» используют как обобщение всех многообразных значений времени применительно к обществу, и этот термин выступает синонимом «исторического времени». «Социальное время есть время существования, функционирования и развития общества как совокупности социальных систем, от человека до социально-экономической формации и человеческого общества в целом. Это-время общественного бытия людей, т. е. их материальная деятельность и отношения, в которые они вступают в процессе этой деятельности» [1, с.9]. Время - способ существования социальных процессов, лежащий в основе их. Время общества получает разнообразные общественные характеристики и имеет многоуровневую структуру. Сущность социального времени определяется сущностью времени вообще [7].

Н.Н.Трубников отмечает, что время как «элемент физического описания реальности, как одна из координат некоторой движущейся точки, и время как определенного рода величина и мера человеческой жизни, как величина и мера социально-исторического бытия людей, как мера человеческого ощущения жизни или, иначе, время как параметр физического измерения длительности физических событий и время как общее условие человеческого бытия - не одно и тоже время. В одном случае это физическая реальность, а в другом - реальность человеческой жизнедеятельности, социально-исторического бытия людей» $[10$, с.6]. Он выделяет время естественнонаучного описания, которое характеризуется определенными величинами измерения, деления и счета; время человеческого определения, которое характеризуется величинами изменения, определения и связи и время социальноисторического бытия, считая его самым фундаментальным и значимым для нас. Оно не равномерно - это время начала и конца. С точки же зрения современного постмодернизма, к которой склоняемся и мы, более значимым является время человеческого определения, так как именно оно задает мировосприятие субъекта.

Г.Е.Зборовский определяет социальное время как такую форму «общественного бытия, которая выступает необходимым условием человеческой деятельности, ее структурной расчлененности и исторического развития с учетом продолжительности процессов» $[4$, с. 129].

Категории времени в той или иной культуре будут различаться по 
своему содержанию в зависимости от того, какие признаки будут входить в это содержание на каждом этапе. Это определяется уровнем развития практики, науки, господствующими ценностными ориентациями. Например, коренная перестройка временных категорий в эпоху Нового времени связана с выдвижением на первый план в их содержании признаков, ранее не использовавшихся (необратимость времени, однородность). Выражением относительной самостоятельности и специфики социального времени является его гетерогенность и полиритмичность.

Понятно, что социально-историческое время не может быть простым аналогом природного времени, поскольку связано с деятельностью человека как субъекта исторического процесса. Оно обладает субъект-объектным статусом. Рефлексия в сознании может быть очень сложной, но это не значит, что время целиком субъективно. Личностное время обладает неопределенностью, возможностью выбора и связано не только с мировоззренческими осознанными и неосознанными переживаниями времени, но и с самосозиданием, самореализацией. Собственно время - ткань самореализации. Личностное время, как и социальное, относительно, изменчиво и может как замедляться, так и ускоряться, что связано с характером технологий.

Социальное время может быть понято только в единстве его качественных и количественных сторон. При таком подходе время фактически является активным бытием человека. Оно не столько мера его жизни, оно - пространство его развития [8]. Постепенно осваивая ближнее пространство и время, человек организует и упорядочивает его, что создает образец, эталон для освоения космического пространства и времени. Чем более освоено, упорядочено, структурировано ближнее пространство и время, тем более рельефно и отчетливо в сознании структурируется космос. Социальное пространство и время выступают своеобразной схемой видения, сквозь которую воспринимается пространственно-временной континуум.

Общество организует свою деятельность во времени, исходя из целей и потребностей социального развития, в соответствии со сложившейся в каждую эпоху структурой, характером и возможностями деятельности.

В.А.Артемьев описывает социальное время как «совокупное, или суммарное, время существования и деятельности всех членов общества, вступающих в процессе деятельности в разного рода отношения и образующих различные группы» $[1$, с. 10] и понимает его как ресурс, которым располагает любой социальный субъект. В исследовании со- 
циального времени наиболее актуальны такие социальные субъекты как человек, семья, социальная группа, территориальная общность.

И.М. Савельева и А.В. Полетаев выделяют четыре типа представлений о времени, в рамках которых формируется структура «прошлоенастоящее - будущее». Эмпирическое - на основе личного опыта. Семейное, или родовое - на основе родовой памяти, семейных традиций. Сакральное - темпоральные представления формируются на основании мифологических мировоззрений. Историческое время - темпоральные представления формируются на основе исторических знаний о прошлом и моделей будущего [9]. По-видимому, авторы подразумевают, что все четыре типа и составляют социальное время.

Американский философ Дж. Льюис, в свою очередь, выделяет три типа социального времени: организационное время, время взаимодействия и личное время. Все индивиды одновременно существуют в каждом из трех времен [13].

В.П. Яковлев определяет социальное время как время человеческого бытия, время человеческой деятельности. Именно на социальном уровне время обретает глубину и полноту своего содержания. В центре его теории времени - понятие события, которое проходит через сознание людей [11]. Мы полностью согласны с этой трактовкой. Цепь событий, застывая, опредмечивается, и тем самым опредмечивается само время человека. В.П. Яковлев соглашается со своими коллегами в том, что вечная проблема времени предстала в новом измерении, когда началось стремительное движение социального прогресса. Линия жизни человека приобрела больший динамизм, что обнаруживается в формах духовного и практического освоения мира. Субстанция социального времени, с точки зрения российского философа, - это социальная материя и изучение самого разума.

Любопытна его трактовка опредмечивания как перехода времени в пространство, а распредмечивания, соответственно, наоборот. По мнению В.П.Яковлева, объективную основу структурирования социального времени составляют человек - социальное поколение - история общества. Темп субъективного времени зависит от эмоционального отношения человека, что, видимо, затрудняет его анализ.

Время истории - это сами люди, посредством истории творящие сами себя. Оно выступает феноменом сознания. Историческое время поколения определяется событиями и является неповторимым. Таким образом, В.П.Яковлев утверждает, что историческое время является частью социального, и указывает на гетерогенность и полиструктурность последнего [11]. Мы полагаем, что необходимо различать стру- 
ктуру самого социального времени (например, трехступенчатая структура у В.П. Яковлева) и структуру анализа этого времени, то есть рассмотрение социального времени в двух аспектах - как реально существующей конкретно-исторической действительности и как форму мышления, способ организации социальных событий, систему представлений. Это позволит избежать односторонности анализа.

К. Янагида противопоставляет природное время историческому. В историческом времени настоящее время называет практическим, а в центре будущего, с его точки зрения, находится целесообразное время [12]. То есть он не делает разницы между социальным и историческим временем.

И.Т. Касавин поддерживает эту точку зрения, но пишет не о природном времени, а об экологическом. Экологическое время отсчитывается от одного религиозного праздника до другого, каждый из которых приурочен к определенному климатическому сезону, например, традиция засевать - к Пасхе. С этим связана и неравномерность времени: оно течет медленно, ускоряясь к определенной дате, что связано с необходимостью выполнить работу к сроку. Автор демонстрирует связь экологического и структурного времени, приводя очень удачный, на наш взгляд, пример: традиционные осенние свадьбы, зимние зачатия, летне-осенние рождения; то есть от рождения до инициации - детство, от инициации до женитьбы - юность, от женитьбы до внуков и седин - зрелость, потом - старость [5].

С точки зрения А.Я.Гуревича, историческое время [2, с.81] «должно рассматриваться в виде многих рядов, в каждом из которых существует особая длительность, присущая только данному уровню развития. Иначе говоря, время экономического цикла или время демографического цикла - это не то же, что длительность политического развития или период существования данной социальной системы». Иначе говоря, историческое время не едино из-за локализации человеческой практики по отдельным сферам. Социальное время различно не только для различных культур и обществ, оно дифференцируется в рамках каждой социально-культурной системы в зависимости от ее внутренней структуры. Социальное время неодинаково протекает в сознании отдельных классов и групп.

Историческое время, являющееся формой движения общества от одной общественно-экономической формации к другой, характеризуется единством своей цельности, непрерывности (в границах хронологического бытия человека) и прерывности (в рамках отдельных формаций). У А.Я.Гуревича прослеживается мысль о том, что интерес к 
временным характеристикам жизнедеятельности общества перманентно вырастает, т. к. он обусловлен ростом, в первую очередь, экономической значимости фактора времени.

Г.Е. Зборовский утверждает, что структура социального времени явление объективное, порождаемое уровнем развития производительных сил и характером производственных отношений. Социально-психологическое восприятие исторического времени нужно отличать от отражения временных свойств и отношений на уровне теоретического сознания, но в любом случае они связаны. В каждую эпоху в любом обществе для отдельных классов и социальных групп формируется свой стиль, образ использования времени, соответствующий задачам производства, классовым потребностям и установкам. Поэтому правомерно полагать, что наряду с объективными характеристиками социального времени необходимо анализировать субъективные представления о нем [4].

$\mathrm{C}$ нашей точки зрения, очень значимым для анализа является тот факт, что индивидуальное переживание времени накладывает свой отпечаток на отражение временных свойств и отношений на уровне теоретического сознания. Время общества целостно, но также существует расчлененность социального времени, отраженная в его исторически изменяющейся структуре и в индивидуальном переживании.

И.М. Савельева и А.В.Полетаев отмечают, что в работах, посвященных истории представлений о времени, обычно исследуются лишь отдельные аспекты темпорального сознания в конкретный исторический период, или делается попытка описать сознание в целом, и в этом случае обычно подчеркивается смешанный характер темпорального сознания. Видимо, под понятием «темпоральное сознание» авторы подразумевают осознание времени. Набор элементов темпорального сознания достаточно устойчив во времени и в социальном пространстве, хотя их конкретная форма может варьироваться [9].

Как уже отмечалось выше, необходимо рассматривать социальное время в двух аспектах - как реально существующую конкретно-историческую действительность и как форму мышления, способ организации социальных событий, систему представлений. Эта методологическая схема позволяет нам анализировать как субъективную сторону социального времени (представления, бытующие в обществе о природе времени, специфика переживания времени в ту или иную эпоху), так и объективную, куда входят реальные материальные объекты, созданные по общественному запросу, а также исторические события.

Социальное время выступает одним из конкретизирующих понятий 
(наряду с понятиями физического и биологического времени) категории времени. Через категорию времени социальное время оказывается связанным с категориями «пространство», «движение». Эта категория помогает глубже и полнее раскрыть диалектику взаимодействия общества и личности. При этом, как справедливо отмечает А.Я. Гуревич, необходимо помнить, что линейное время - одна из возможных форм социального времени, восторжествовавшая в качестве единственной системы отсчета времени в европейском культурном регионе $[3$, с. 50$]$. Сегодня убыстрение темпа технологических изменений, инспирированных европейской рациональностью, ведет к увеличению скорости социальных изменений, что находит отражение в жизни каждого человека. Рационализм, будучи средством кратчайшего достижения цели (экономия времени), как личностная характеристика, является необходимым требованием успешной жизнедеятельности человека в современном обществе. Определяющим модусом времени становится не настоящее, а будущее - то, что можно спланировать и рассчитать.

В целом мы можем констатировать, что в современной философии нет единого мнения по вопросу структуры социального времени и форм его анализа, поэтому требуется дальнейшее исследование этой темы с учетом социокультурных и технологических изменений, происходящих с современном обществе.

\section{1 Литература}

[1] Артемъев B.A. Социальное время. Проблемы изучения и исследования.- Новосибирск: Наука, 1987.

[2] Гуревич А.Я. Время как проблема истории культуры. // Вопросы философии. - 1969. - №3. - С. 72-84.

[3] Гуревич А.Я. Категории средневековой культуры.-М.: Искусство, 1984.

[4] Зборовский Г.Е. Пространство и время как формы социального бытия. - Свердловск: Изд-во Свердловского юридического института, 1974.

[5] Касавин И.Т. Миграция, Креативность, Текст. - СПб.: Изд. Русского христианского гуманитарного института, 1999. 
[6] Мелюхин С.T. Время // Философский энциклопедический словарь (под ред. И.Т. Фролова). - М.: Советская энциклопедия, 1983. - C. 94-95.

[7] Орлов Г.П. Свободное время: условия развития человека и мера общественного бытия. - Свердловск: Изд-во Уральского университета, 1989.

[8] Осипов А.И. Пространство и время как категории мировоззрения и регуляторы практической деятельности. - Минск: Наука и техника. 1989.

[9] Савельева И.М. Полетаев А.В. История и время. В поисках утраченного. - М.: Языки русской культуры, 1997.

[10] Трубников Н.Н. Время человеческого бытия. - М.: Наука, 1987.

[11] Яковлев В.П. Социальное время. - Ростов-на-Дону: Изд-во Ростов. гос. Ун-та, 1980.

[12] Янагида К. Философия истории.-М.: Прогресс, 1969.

[13] Lewis J.D., Weigart A. J. Structures and meaning of Social Time // Social Forces. - 1981. - Vol. 60. - № 2. - P. 433-462. 